Article

\title{
Conductomeric Evaluation of the Release Kinetics of Active Substances from Pharmaceutical Preparations Containing Iron Ions
}

\author{
Anna Lisik and Witold Musiał *(D) \\ Department of Physical Chemistry, Pharmaceutical Faculty, Wroclaw Medical University, Borowska 211, \\ 50-556 Wroclaw, Poland; anna.lisik@student.umed.wroc.pl \\ * Correspondence: witold.musial@umed.wroc.pl; Tel.: +48-71-784-02-28
}

Received: 18 January 2019; Accepted: 27 February 2019; Published: 3 March 2019

\begin{abstract}
The aim of this study was to verify the effect of the formulation on the release kinetics of active substances from preparations containing iron ions using in-line conductivity measurements. A simple, fast method was developed and may be applied for detailed evaluation of some kinetics factors obtained from the release data. Four different equations were used: zero-order equation, first-order equation, models: Korsmeyer-Peppas and Hixson-Crowell. Values of the determined half-time release for zero and first-order kinetic models ranged from 11.56 to $89.97 \mathrm{~min}$. In the case of analysis according to these typical models, the values of the square root of the correlation coefficients were included between 0.9916 and 0.9995 . The results transformed for the Hixson-Crowell model as constant release Ks, ranged between 0.0160 and 0.0437 . The values of the respective calculated squares of the correlation coefficient ranged from 0.9933 to 0.9959 . The determined release rate constants according to the Korsmeyer-Peppas model were between 0.0023 and 0.1630 . The coefficients ' $n$ ' of the Korsmeyer-Peppas equation did not exceed 1.2 with the corresponding $\mathrm{r}^{2}$ values $0.9408-0.9960$. Obtained results confirmed that the method is applicable for evaluation of selected drug compositions containing iron ions.
\end{abstract}

Keywords: electric conductivity; release kinetics; drug release models; drug dissolution; controlled drug release; electrochemistry; metal complexes

\section{Introduction}

The variety of analytical methods is applied to obtain detailed insight into the qualitative and quantitative aspects of drug release from the solid formulations. Numerous authors proposed high performance liquid chromatography (HPLC) in its different versions, e.g.: HPLC with ultra violet (UV) [1] or diode-array detector (DAD) detection [2], nowadays frequently combined [3]. The wide possibilities in the detection of released bioactives include: evaporative light scattering detector (ELSD) [4], refractive index detector [5], contactless conductivity detector [6], the reversed phase HPLC [7], ultra HPLC [8], as well as gas chromatography (GC) [9] and liquid chromatography-mass spectrometry (LCMS) [10], are also applied in the field of the assessment of the bioctives release from the formulation. Anyway, the most applied methods include UV-Vis [11,12] and atomic absorption spectrometry (AAS) [13], as useful and cost-effective methods. The above-mentioned analytical methods often enable frequent recording of increasing concentrations of the analyte in dissolution medium. In our department, we evaluated a new method designed for in-line assessment of release of bioactives from solid drug forms. The method was partially validated, and thus may be applied for detailed evaluation of some kinetics factors obtained from release data [14]. The data obtained by continuous multiplying measurements result in detailed course of release plot and may be used 
for kinetic model calculations. In most cases, kinetic models are used when new drug formulation is evaluated to confirm the effectiveness of drug release. Selection of the appropriate mathematical model when developing new pharmaceutical products or elucidation of the drug release mechanisms strongly depends on the precision and accuracy of the model. In selected cases, the use of a simple mathematical model is sufficient. However, the release data, gathered as release profiles, may be used for preliminary reflection of bioavailability of the drug in specific drug form. In this research, four equations were used: zero-order equation, first-order equation, Korsmeyer-Peppas, and Hixson-Crowell, as presented in Table 1.

Table 1. Selected kinetic models applied for the evaluation of release kinetics.

\begin{tabular}{ccc}
\hline Kinetic Model & Equation & Source \\
\hline zero-order & $\mathrm{C}_{\mathrm{t}}=\mathrm{C}_{0}+k_{0} t$ & {$[15-17]$} \\
first-order & $\log \mathrm{C}_{0}-\log \mathrm{C}_{\mathrm{t}}=\frac{\mathrm{k}_{1} \mathrm{t}}{2.303}$ & {$[15-17]$} \\
Hixson-Crowell & $\mathrm{W}_{0}^{\frac{1}{3}}-\mathrm{W}_{\mathrm{t}}^{\frac{1}{3}}=\mathrm{kt}$ & {$[15-17]$} \\
Korsmeyer-Peppas & $\mathrm{F}=\left(\frac{\mathrm{M}_{\mathrm{t}}}{\mathrm{M}}\right)=\mathrm{K}_{\mathrm{m}} \cdot \mathrm{t}^{\mathrm{n}}$ & {$[15-17]$} \\
\hline
\end{tabular}

$\mathrm{k}_{0}$-zero-order constant; $\mathrm{k}_{1}$-first-order constant; $\mathrm{C}_{0}$-an initial concentration of released drug; $\mathrm{C}_{\mathrm{t}}$-the concentration of drug released in the time; $\mathrm{W}_{0}$-the initial mass of drug in the pharmaceutical dosage form; $\mathrm{W}_{\mathrm{t}}$-the remaining mass of drug in the pharmaceutical dosage form at time $\mathrm{t} ; \mathrm{k}$ - the constant value combine the surface and volume relation; $\mathrm{F}$ - fraction of drug released at time $t ; \mathrm{M}_{\mathrm{t}}$-the mass of drug released at time $\mathrm{t} ; \mathrm{M}$-the total mass of drug in dosage form; $\mathrm{K}_{\mathrm{m}}$ - kinetic constant; $\mathrm{n}$-diffusion or release exponent; $\mathrm{t}$ - time in hours.

In the zero-order model the constant amount of active pharmaceutical substance (API) is released per time unit, whereas in the first-order model there is a constant proportion of drug released per time unit. However, the first-order process depends on the concentration, and the zero-order kinetics is actually independent of concentration. Both models are valuable when the pharmacokinetic study is concentrated on differentiation of potential preparations, which may be applied as controlled release products. The ideal situation may reflect the zero-order process, when the initial and actual drug concentration in the formulation does not influence the release rate. More detailed models may enable approximation of the mechanism which are influencing the drug amounts released into the dissolution medium. In 1983 Korsmeyer, Gurny, Doelker, Buri, and Peppas developed a model for description of drug release from polymeric systems. The mechanism of drug release may be detailed by adoption of the initial $60 \%$ of the semi-empirical model, and is known as the Korsmeyer-Peppas model. The value ' $\mathrm{n}$ ' in the model reflects the possible release mechanisms of drug according to Table 2 [15-21].

Table 2. The variability of release exponent (n) and the respective release mechanisms.

\begin{tabular}{ccc}
\hline $\mathbf{n}$ & Drug Transport Mechanism & Rate as a Function of Time $(\mathbf{t})$ Transformation \\
\hline 0.5 & Fickian diffusion & $\mathrm{t}^{-0.5}$ \\
$0.45<\mathrm{n}=0.89$ & Non-Fickian transport & $\mathrm{t}^{\mathrm{n}-1}$ \\
0.89 & Case II transport & $\mathrm{t}$ \\
$>0.89$ & Super case II transport & $\mathrm{t}^{\mathrm{n}-1}$ \\
\hline
\end{tabular}

The calculation of the value of exponent ' $n$ ' may be performed on the plot part where: $M_{t} / M_{\infty}$ $<0.6$. In 1931 Hixson and Crowell recognized that the rate of dissolution depends on the surface contacting with the applied solvent. The increase in the surface area results in faster dissolution. This model fits well to the drug release from the tablets, due to the respective changes in surface area and diameter [15-21].

The purpose of the following study was to adjust the selected kinetic models, to the results obtained from the conductometric measurements of the release of iron ions from three drugs available on the European pharmaceutical market. The previously developed new analytical method was partially validated and applied in the present study [14]. 


\section{Materials and Methods}

\subsection{Materials}

Three various preparations, obtained from the market, containing iron ions were used in the study. Composition FEP1 contained $100 \mathrm{mg}$ of iron as ferrous sulfate and $60 \mathrm{mg}$ of ascorbic acid, in the form of tablet with prolonged release of bioactives. Composition FEP2 included $105 \mathrm{mg}$ of iron ions as ferrous sulfate, and $0.35 \mathrm{mg}$ of folic acid. FEN3 included iron as iron (II) gluconate corresponding to $23.2 \mathrm{mg}$ of iron, tablets form. Deionized water from dedicated Hydrolab HLP20UV device (Hydrolab Sp. z o.o. Sp.K., Straszyn, Poland) was used in all the conductivity assays [14].

\subsection{Dissolution Test}

The dissolution tester Erweka DT 700 (Erweka GmbH, Heusenstamm, Germany) with paddle at $75 \mathrm{rpm}$ was used, for the determination of the formulation dissolution, according to pharmacopoeial standards. Evaluated tablets were placed in the bottom of dissolution vessels and dissolution test according to the Ph. Eur. was performed in this experiment [22]. Purified water of $37^{\circ} \mathrm{C}$ as a dissolution medium, in a volume of $900 \mathrm{~mL}$ was used during entire experiment [14].

\subsection{Electric Conductivity Method Conditions}

Sample solution preparation: sample solution preparations were obtained from the dissolution studies performed via dissolution paddle. Conductivity probe (Elmetron conductivity meter CC-505 with conductivity probe EC-70, Elmetron, Zabrze, Poland) was placed in the middle of dissolution vessel and the result was read directly from the conductivity meter in $\mu \mathrm{s} \cdot \mathrm{cm}^{-1}$. Measurement using conductivity meter was performed in every $5 \mathrm{~min}$ until the equilibrium state was reached for each composition: $180 \mathrm{~min}$ for composition FEP1 and FEP2 and $50 \mathrm{~min}$ for composition FEN3. The study was performed in six vessels on every composition, and the calibration curves for conductivity evaluation were prepared from the powdered solid formulations. The electric conductivity method has been developed and partially validated for all three drug compositions as per ICH guidelines [23], and presented in former paper [14].

\subsection{Calculations}

The basic calculations were performed in the Excel Worksheet enhanced by trial Analytic Solver Basic by FrontlineSolvers. Four basic kinetic models were applied for the calculations: zero-order, first-order, Korsmeyer-Peppas, and Hixson-Crowell. Determination coefficients for obtained rates, and specific factors were calculated as squares of respective correlation coefficients. The data for the zero-order, first-order and Hixson-Crowell kinetics were evaluated "duo modo": firstly, the basic data were calculated according to the specified equation, as presented in Table 1, numbers 1-3. The fitting segments, represented by straight lines, were used as a basis for sketching the respective kinetics.

\section{Results}

The process of drug substance release from the tested tablets is illustrated in Figure 1. The preparation A (FEP1) released almost $100 \%$ of bioactive within about $180 \mathrm{~min}$, while during the first $100 \mathrm{~min}$ the process is close to the exponential function. In the case of preparation B (FEP2), in the first $30 \mathrm{~min}$ no release of the drug substance was observed; after this period the progress of release was curvilinear, although the curve was rather flattened and slightly deviates from the course of the straight line. As in the case of preparation A, almost all of the active substance proceeds into the dissolution medium after about $180 \mathrm{~min}$. The release of the active substance from preparation C (FEN3) was definitely different. The active substance from formulation $C$ released rapidly, reaching a plateau at $40 \mathrm{~min}$, which corresponded to about $100 \%$ of released analyte. The original, non-transformed data, obtained in the course of in-line conductivity measurements, are presented in Figure 1D-F. 

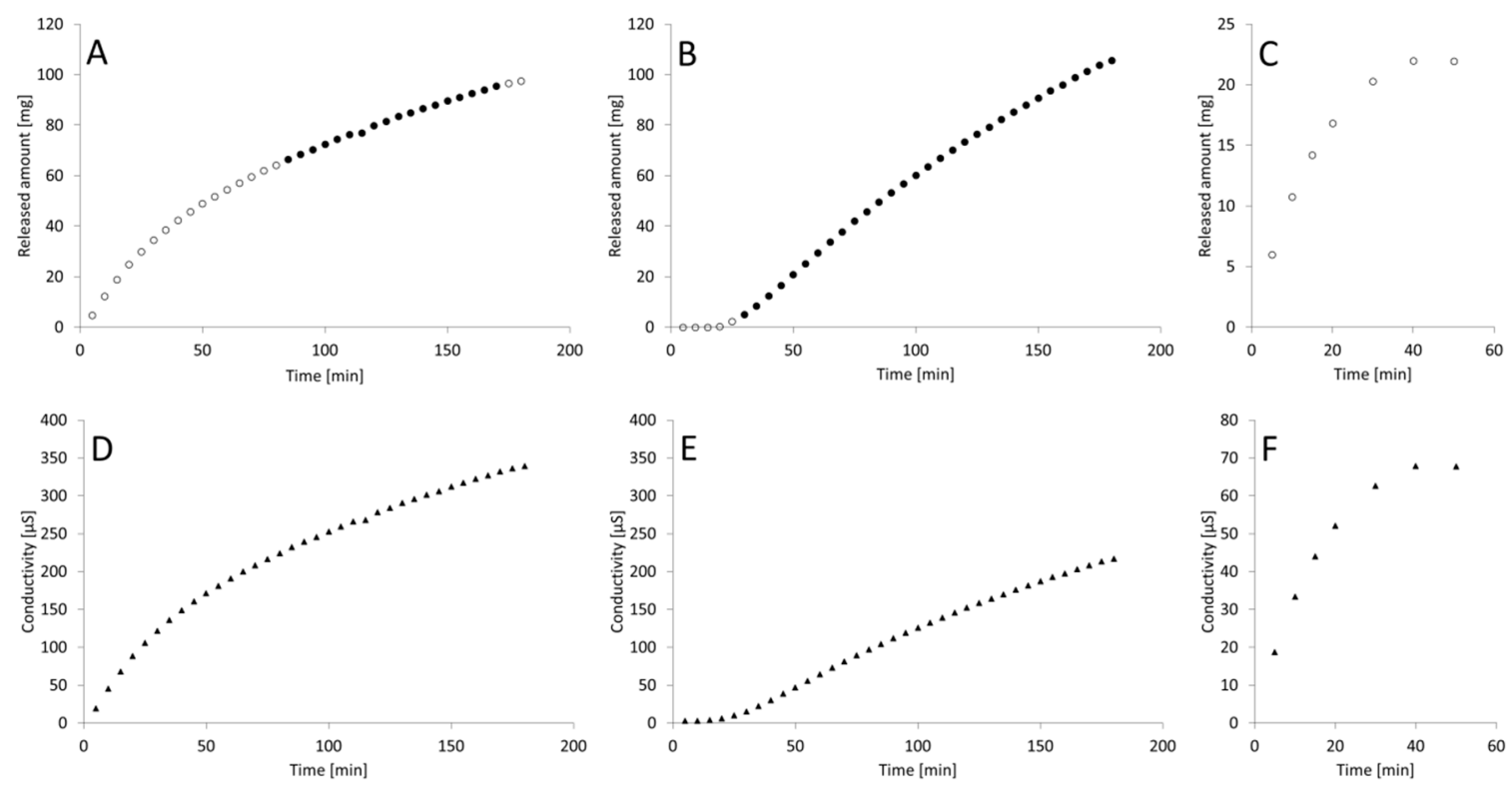

Figure 1. The process of API release from tested preparations containing ferric ions, determined by the conductometric method. A-C: release profiles of preparations FEP1 (A), FEP2 (B), FEN3 (C), $\bigcirc$-experimental data; $\bullet$ - experimental data applied for the evaluation of approximated zero-order kinetics. D-C: raw conductivity results ( $\mathbf{\Delta}$ ) for FEP1 (D), FEP2 (E), FEN3 (F).

Table 3 summarizes the calculated parameters of kinetic equations describing the process of API release from individual formulations: FEP1, FEP2, FEN3. In pursuance of the kinetic calculations carried out according to the 0 order and 1 order kinetic model, the process of API release from FEP1 was characterized by two distinct phases with specific constants, whereas the release from FEP2 and FEN3 could be clearly presented as a one-step process. Values of the determined half-time release for these kinetic models ranged from 11.56 to $89.97 \mathrm{~min}$. Table 1 also presents the values of the square root of the correlation coefficient, informing about the adjustment of the applied model to the observed progress of the examined process. In the case of analysis according to these typical models the values were included between 0.9916 and 0.9995 . The results of observations collected in subsequent columns were transformed for the Hixson-Crowell model as constant release Ks, ranged between 0.0160 and 0.0437 with the highest constant for FEN3. The values of the respective calculated squares of the correlation coefficient ranged from 0.9933 to 0.9959 . The determined release rate constants according to the Korsmeyer-Peppas model were from very low 0.0023 for FEP2 to 0.1630 for FEN3. The coefficients ' $\mathrm{n}$ ' of the Korsmeyer-Peppas equation did not exceed 1.2, with the corresponding $\mathrm{r}^{2}$ values from 0.9408 to 0.9960 . 
Table 3. Basic kinetic parameters of the process of API kinetics release from the tested preparations: FEP1, FEP2, and FEN3.

\begin{tabular}{|c|c|c|c|c|c|c|c|c|c|}
\hline Composition & $\mathrm{k}_{1}(1 / \mathrm{min})$ & $\mathrm{k}_{0}(\mathrm{mg} / \mathrm{min})$ & $t_{0.5}(\min )$ & $\mathrm{r}^{2}$ & $\mathrm{~K}_{\mathrm{S}}$ & $\mathbf{r}^{2}$ & \multicolumn{2}{|c|}{ Korsmeyer-Peppas $K_{K P} n$} & $\mathbf{r}^{2}$ \\
\hline $\begin{array}{l}\text { FEP1, 1st stage } \\
\text { FEP1, 2nd stage }\end{array}$ & $\begin{array}{c}0.174 \pm 0.0160 \\
-\end{array}$ & $\begin{array}{c}- \\
0.315 \pm 0.022\end{array}$ & $52.00^{(b)} \pm 2.67$ & $0.9995^{\text {(a) }} \pm 0.0011$ & $0.0160 \pm 0.0013$ & $0.9933^{(b)} \pm 0.4200$ & $0.0512 \pm 0.0082$ & $0.574 \pm 0.029$ & $0.9960 \pm 0.3633$ \\
\hline FEP2 & - & $0.680 \pm 0.020$ & $89.77 \pm 4.09$ & $0.9916 \pm 0.0027$ & $0.0180 \pm 0.0009$ & $0.9959^{\text {(c) }} \pm 0.1360$ & $0.0023 \pm 0.0008$ & $1.192 \pm 0.061$ & $0.9837 \pm 0.0678$ \\
\hline FEN3 & $0.0544 \pm 0.0031$ & - & $11.56 \pm 0.54$ & $0.9945 \pm 0.0034$ & $0.0437 \pm 0.0045$ & $0.9956^{(\mathrm{d})} \pm 0.3719$ & $0.1630 \pm 0.016$ & $0.472 \pm 0.025$ & $0.9408 \pm 0.7519$ \\
\hline
\end{tabular}

$\mathrm{k}_{0}$-zero-order rate, $\mathrm{k}_{1}$-first-order rate, $\mathrm{t}_{0.5}$-half-release time, $\mathrm{K}_{\mathrm{S}}$-Hixson-Crowell release rate, $\mathrm{K}_{\mathrm{KP}}$-Kosmeyer-Peppas release rate, $\mathrm{n}$ - $\mathrm{n}$ factor in Korsmayer-Peppas model, $\mathrm{r}^{2}$ —determination coefficient, ${ }^{(\mathrm{a})}$ —calculated for best fitted section of the data set, ${ }^{(\mathrm{b})}$ - calculated for entire data set, ${ }^{(\mathrm{c})}$ — calculated for best fitted section of the data set, ${ }^{(\mathrm{d})}$ —calculated for entire data set. 


\section{Discussion}

Figure 2 presents the course of kinetic curves describing the process of API release for individual preparations (FEP1, FEP2 and FEN3) according to the proposed Hixson-Crowell and Korsmeyer-Peppas models.
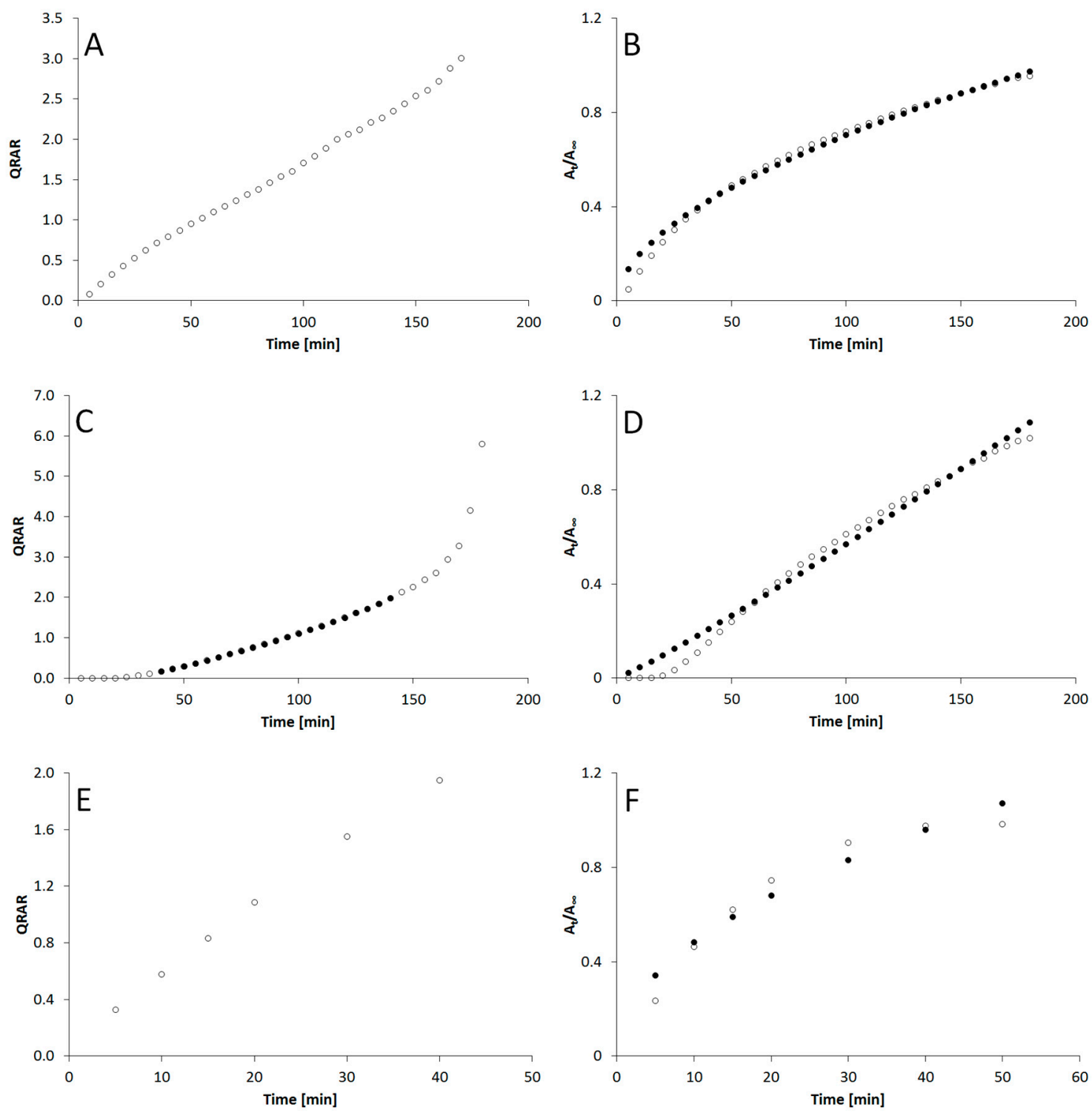

Figure 2. The Hixson-Crowell (A,C,E) and Korsmeyer-Peppas (B,D,F) kinetics, applied to evaluated preparations: FEP1 (A,B), FEP2 (C,D) and FEN3 (E,F) respectively. The filled circles on panel C represent the partial fitting of the data to the Hixson-Crowell model in the case of FEP1. The filled circles on the panels B, D, F represent the data calculated for the Korsmeyer-Peppas model according to the best fitted section of the graph in the SOLVER application, whereas the empty circles on these panels represent the surrogate data transformed according to the model. The empty circles on the axis $\mathrm{x}$ on panel $\mathrm{D}$ should not be included for the consideration of Korsmeyer-Peppas model for FEP2. QRAR - cubic root of the amount of released drug, $A_{t} / A_{\infty}$ the ratio of the amount of drug released at time $t$ to the total released amount of drug.

Based on dependence of the substance amount released in the time (Figure 1A) it can be concluded that from the preparation A the active substance is released in a mixed manner: (a) calculations performed with the Solver program allowed to determine that the API release from this preparation in 
the first stage i.e. up to about $100 \mathrm{~min}$ of the process is characterized by the advantage of the first-order kinetics. However, after this period, the process is first-order in the next $80 \mathrm{~min}$. Figure $3 \mathrm{~A}$ shows the change of participation of first-order kinetics in the whole process and zero-order in the overall process depending on time (Figure 3B).
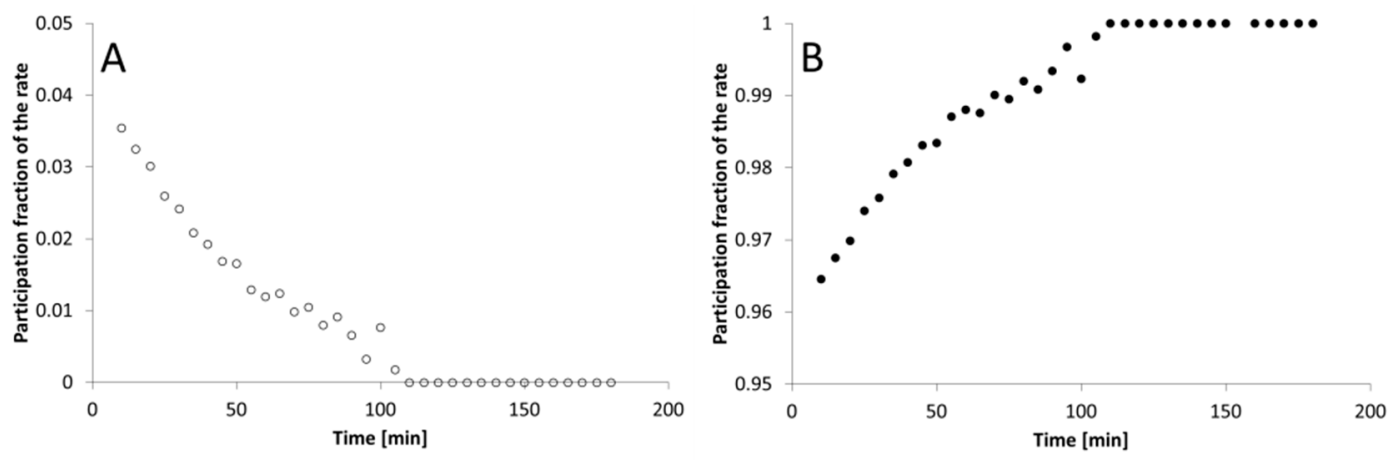

Figure 3. Decrease of $\mathrm{k}_{1}$ participation in the kinetics process (A), and increase of $\mathrm{k}_{0}$ participation in the kinetics process $(\mathbf{B})$ in the total release process depending on time for the preparation FEP1.

The diversity of this process can be summarized by the equation:

$$
\Delta \mathrm{C}=\mathrm{Ak}_{1} \times \mathrm{C}_{0} \Delta \mathrm{t}+\mathrm{Bk}_{0} \times \Delta \mathrm{t}
$$

where: A-fraction of the 1st order kinetics at a given moment of the release process, $\mathrm{B}$ - fraction of the 0 th order kinetics at a given moment of the release process, $t$ - time, $\mathrm{C}$ concentration at a specific moment, $\mathrm{C}_{0}$-initial concentration, $\mathrm{k}_{0}$-zero-order rate constant, $\mathrm{k}_{1}$ - first-order rate constant.

The observed process may reflect tablet technological design which is a compact tablet covered by thin polymer film and contains both the initiating and the maintenance dose. The release process graph for the Hixson-Crowell model (Figure 2A) does not confirm the complete compatibility of the release kinetics with the surface drug loss, although relatively high $\mathrm{r}^{2}$ coefficient values were obtained for this model (Table 3). According to the value 0.574 of coefficient $n$ for the Korsmeyer-Peppas model preparation A releases the active substance both as a result of diffusion and as a result of erosion. Reference values for so-called anomalous transport are within the limits between 0.5 and 1.0. The release process according to this model is given in Figure 2B.

In the case of preparation $B$ independently of the amount of active substance in the donor compartment, the release process was clearly observed which can be related to the limiting effect of a thick water-insoluble coating. Also the lag-time clearly observed in the case of preparation B indicates the important role of the coating in the drug substance release in this case compared to preparation $\mathrm{A}$, the graph prepared for the Hixson-Crowell model presented as a straight line in the limited extent which indicates the effect of the formulation surface loss on the release rate at the time (Figure 2C); It should be clearly stated that the process consistent with this model was observed only in a limited period of time between 40 and $140 \mathrm{~min}$. Confirmation of the surface loss as a release controlling factor is here a high value of the ' $\mathrm{n}$ ' coefficient in the Korsmeyer-Peppas model exceeding the value of 1.0 called the super case II transport (Table 3, Figure 2D) [24].

The active substance of preparation $C$ was released according to the first-order kinetics. The release rate decreased over the time, corresponding to the situation with unmodified but long-term releasing tablets. Formulation $\mathrm{C}$ was characterized by a strongly linear graph plot for the Hixson-Crowell model almost in the entire period of time studied as shown in Figure 2E. This suggests an outstanding conection between the loss of product surface and the amount of the therapeutic substance released. However, this fact is not directly confirmed in the process flow compared to the Korsmeyer-Peppas model; the value of the corresponding factor ' $n$ ' for the preparation $C$ does not exceed 0.5 , ie the 
characteristic value for the diffusion described by the Fick equation. The respective release process is illustrated in Figure 2F.

Future evaluation of the conductometric assays should involve analysis of subsequent preparations containing iron ions to wider the application field of the above-presented method. Development of a database with the results of conductometric assays for excipients may significantly facilitate the pharmaceutical analytics with the hereby presented method for numerous solid forms containing other ions. The limitations of the method include variability of the conductivity of aqueous solvent, and influence of impurities on the conductivity of the samples.

\section{Conclusions}

Application of conductometric measurements enables comparative assessment of the drug release kinetics from preparations containing iron ions. The proposed analytical method is applicable for the evaluation of the release process in accordance with complex kinetic models including zero-order and 1st kinetics, as well as KP and HC models. The revealed variability of kinetics via conductometric method enables differentiation of pharmaceutical preparations according to the drug release mode on the molecular level.

Author Contributions: Conceptualization, W.M. and A.L.; Methodology, W.M. and A.L.; Software, W.M. and A.L.; Validation, W.M. and A.L.; Formal Analysis, W.M. and A.L.; Investigation, W.M. and A.L.; Resources, W.M. and A.L.; Data Curation, W.M. and A.L.; Writing-Original Draft Preparation, W.M. and A.L.; Writing-Review \& Editing, W.M. and A.L.; Visualization, W.M. and A.L.; Supervision, W.M; Project Administration, W.M.; Funding Acquisition, W.M.

Funding: This research was funded by Wroclaw Medical University, grant number STD060.18.15.

Conflicts of Interest: The authors declare no conflict of interest. The funders had no role in the design of the study; in the collection, analyses, or interpretation of data; in the writing of the manuscript, or in the decision to publish the results.

\section{References}

1. Vella, J.; Bussuttil, F.; Sammut Bartolo, N.; Sammut, C.; Ferrito, V.; Serracino Inglot, A.; Azzopardi, L.M.; La Ferla, G. A simple HPLC-UV method for the determination of ciprofloxacin in human plasma. J. Chromatogr. B 2015, 989, 80-85. [CrossRef] [PubMed]

2. Carlucci, G.; Di Federico, L.; Iuliani, P. HPLC-DAD method for the simultaneous determination of zofenopril and hydrochlorothiazide in oral pharmaceutical formulations. J. Sep. Sci. 2010, 33, 1717-1722. [CrossRef] [PubMed]

3. Bilodeau, L.; Dufresne, G.; Deeks, J.; Clément, G.; Bertrand, J.; Turcotte, S.; Robichaud, A.; Beraldin, F.; Fouquet, A. Determination of vitamin D3 and 25-hydroxyvitamin D3 in foodstuffs by HPLC UV-DAD and LC-MS/MS. J. Food Compos. Anal. 2011, 24, 441-448. [CrossRef]

4. Karlsson, G.; Winge, S.; Sandberg, H. Separation of monosaccharides by hydrophilic interaction chromatography with evaporative light scattering detection. J. Chromatogr. A 2005, 1092, 246-249. [CrossRef] [PubMed]

5. Sang-Ho, Y.; Jay-lin, J. Molecular weights and gyration radii of amylopectins determined by high-performance size-exclusion chromatography equipped with multi-angle laser-light scattering and refractive index detectors. Carbohydr. Polym. 2002, 49, 307-314. [CrossRef]

6. Coufal, P.; Zuska, J.; Van de Goor, T.; Smith, V.; Gaš, B. Separation of twenty underivatized essential amino acids by capillary zone electrophoresis with contactless conductivity detection. Electrphoresis 2003, 24, 671-677. [CrossRef] [PubMed]

7. Zu, Y.; Li, C.; Fu, Y.; Zhao, C. Simultaneous determination of catechin, rutin, quercetin kaempferol and isorhamnetin in the extract of sea buckthorn (Hippophae rhamnoides L.) leaves by RP-HPLC with DAD. J. Pharmaceut. Biomed. 2006, 41, 714-719. [CrossRef] [PubMed]

8. Boussèsa, C.; Fereyb, L.; Vedrinesa, E.; Gaudin, K. Using an innovative combination of quality-by-design and green analytical chemistry approaches for the development of a stability indicating UHPLC method in pharmaceutical products. J. Pharmaceut. Biomed. 2015, 115, 114-122. [CrossRef] [PubMed] 
9. Del Barrio, M.A.; Hu, J.; Zhou, P.; Cauchon, N. Simultaneous determination of formic acid and formaldehyde in pharmaceutical excipients using headspace GC/MS. J. Pharmaceut. Biomed. 2006, 41, 738-743. [CrossRef] [PubMed]

10. Petrović, M.; Hernando, M.D.; Díaz-Cruz, M.S.; Barceló, D. Liquid chromatography-tandem mass spectrometry for the analysis of pharmaceutical residues in environmental samples: A review. J. Chromatogr. A 2005, 1067, 1-14. [CrossRef] [PubMed]

11. Licht, S.; Naschitz, V.; Halperin, L.; Halperin, N.; Lin, L.; Chen, J.; Ghosh, S.; Liu, B. Analysis of ferrate(VI) compounds and super-iron Fe(VI) battery cathodes: FTIR, ICP, titrimetric, XRD, UV/VIS, and electrochemical characterization. J. Power Sources 2001, 101, 167-176. [CrossRef]

12. Johansson, J.; Cauchi, M.; Sundgren, M. Multiple fiber-optic dual-beam UV/Vis system with application to dissolution testing. J. Pharmaceut. Biomed. 2002, 29, 469-476. [CrossRef]

13. Abarcaa, A.; Canfranca, E.; Sierraa, I.; Marina, M.L. A validated flame AAS method for determining magnesium in a multivitamin pharmaceutical preparation. J. Pharmaceut. Biomed. 2001, 25, 941-945. [CrossRef]

14. Lisik, A.; Prescha, A.; Cavlaz, L.E.; Grajeta, H.; Musiał, W. The evaluation of alternative method of ferrous ions assessment in pharmaceutical preparations. Monatsh. Chem. 2018, 149, 931-937. [CrossRef] [PubMed]

15. Dash, S.; Murthy, N.P.; Nath, L.; Chwdhury, P. Kinetic modeling on drug release from kinetic controlled drug delivery systems. Acta Pol. Pharm. 2010, 67, 217-223. [PubMed]

16. Siepmann, J.; Siepmann, F. Mathematical modeling of drug delivery. Int. J. Pharm. 2008, 364, 328-343. [CrossRef] [PubMed]

17. Shaikh, H.K.; Kshirsagar, R.V.; Patil, S.G. Mathematical models for drug release characterization: A review. World J. Pharm. Pharm. Sci. 2015, 4, 324-338.

18. Costa, P.; Sousa Lobo, J.M. Modeling and comparison of dissolution profiles. Eur. J. Pharm. Sci. 2001, 13, 123-133. [CrossRef]

19. Kalam, M.A.; Humayun, M.; Parvez, N.; Yadav, S.; Garg, A.; Amin, S.; Sultana, Y.; Ali, A. Release kinetics of modified pharmaceutical dosage forms: A rewiev. CJP Sci. 2007, 1, 30-35.

20. Siepmann, J.; Siepmann, F. Modeling of diffusion controlled drug delivery. J. Control. Release 2012, 160, 351-362. [CrossRef] [PubMed]

21. Peppas, N.A.; Narasimhand, B. Mathematical models in drug delivery: How modeling has shaped the way we design new drug delivery systems. J. Control. Release 2014, 190, 75-81. [CrossRef] [PubMed]

22. Council of Europe. European Pharmacopoeia Commission. Dissolution test for solid dosage forms (Chapter 2.9.3). In European Pharmacopoeia, 5th ed.; Council of Europe: Strasburg, Germany, 2005; p. 20903.

23. International Conference on Harmonisation of Technical Requirements for Registration of Pharmaceuticals for Human Use: Validation of Analytical Procedures: Text and Methodology Q2(R1); Current Step 4 Version Parent Guideline dated 27 October 1994 (Complementary Guideline on Methodology Dated 6 November 1996 Incorporated in November 2005). Available online: https: / www.ich.org/fileadmin/Public_Web_Site/ ICH_Products/Guidelines/Quality/Q2_R1/Step4/Q2_R1_Guideline.pdf (accessed on 16 October 2017).

24. Holowka, E.P.; Bhatia, K.S. Controled Released Systems. In Drug Delivery: Materials Design and Clinical Perspective, 1st ed.; Springer-Verlag: New York, NY, USA, 2014; pp. 7-14, ISBN 978-1-4939-1998-7.

(C) 2019 by the authors. Licensee MDPI, Basel, Switzerland. This article is an open access article distributed under the terms and conditions of the Creative Commons Attribution (CC BY) license (http://creativecommons.org/licenses/by/4.0/). 